AUTHOR QUERY FORM

\begin{tabular}{|l|l|l|}
\hline & Journal: CAR & Please e-mail or fax your responses and any corrections to: \\
\hline & & E-mail: corrections.essd@elsevier.sps.co.in \\
\hline ELSEVIER & Article Number: 5704 & Fax: $+\mathbf{3 1} 204852799$ \\
\hline
\end{tabular}

Dear Author,

Please check your proof carefully and mark all corrections at the appropriate place in the proof (e.g., by using on-screen annotation in the PDF file) or compile them in a separate list. To ensure fast publication of your paper please return your corrections within 48 hours.

For correction or revision of any artwork, please consult http://www.elsevier.com/artworkinstructions.

Any queries or remarks that have arisen during the processing of your manuscript are listed below and highlighted by flags in the proof. Click on the ' $Q$ ' link to go to the location in the proof.

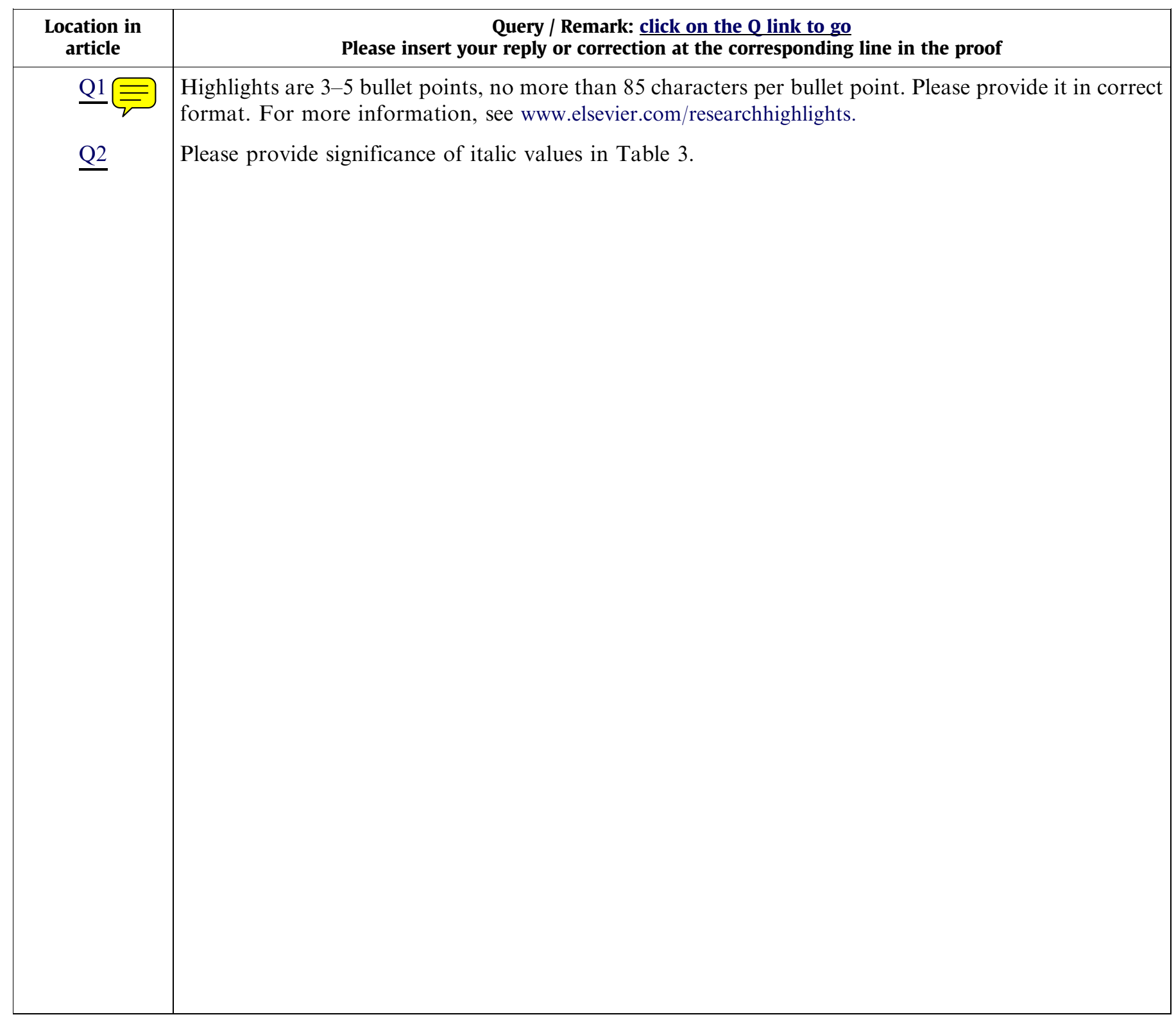

Thank you for your assistance. 


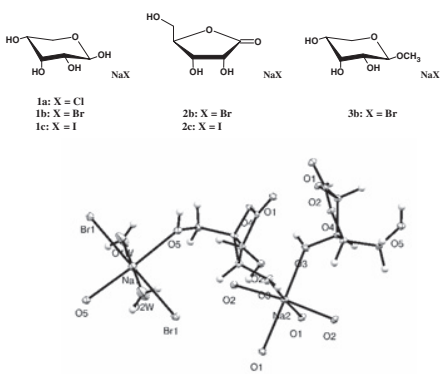

\section{Research highlights}

Crystalline complexes of D-ribose, D-ribono-1,4-lactone and methyl $\beta$-D-ribopyranoside with sodium halogenides were synthesized and three crystal structures determined $\downarrow$ The D-ribono-1,4-lactone complexes have varying stoichiomeries and water content $\square$ The crystal structures of sodium halogenide complexes display regular cation coordination $>$ The methyl $\beta$-D-ribopyranoside $1: 1$ complex does not contain water and has unusual coordination $>$ The hydrated complexes have extensive hydrogen bonding while only meager HB contacts are Q1 in the non-hydrated one $\rightarrow$ Such complexes can be easily prepared in solid state reactions in a ball mill.

in the non-hydrated one $>$ Such complexes can be easily prepared in solid state 


\title{
Sodium halide complexes of ribose derivatives and their unusual crystal structures
}

\author{
Mátyás Czugler ${ }^{\mathrm{a}, *}$, István Pintér ${ }^{\mathrm{b}}$ \\ ${ }^{a}$ Chemical Research Center, Institute of Structural Chemistry, Hung. Acad. Sci., Pusztaszeri u. 59-67, Budapest H-1025, Hungary \\ ${ }^{\mathrm{b}}$ Eötvös Loránd University, Chemical Institute, Department of Organic Chemistry, Structural Chemistry and Biology Laboratory, Budapest 1117, Hungary
}

\section{A R T I C L E I N F O}

\section{Article history:}

Received 31 January 2011

Received in revised form 7 March 2011

Accepted 8 March 2011

Available online $\mathrm{xxxx}$

This paper is dedicated to Professor András Lipták on the occasion of his 75th birthday

\section{Keywords:}

$20 \quad$ Ribose derivatives

Sodium halide complexes

$\mathrm{X}$-ray crystal structures

\begin{abstract}
A B S T R A C T
Crystalline complexes of D-ribose, D-ribono-1,4-lactone and methyl $\beta$-D-ribopyranoside with sodium halides were synthesized and some of their crystal structures determined. Crystal structures of two lactone complexes and a methyl $\beta$-D-ribopyranoside reveal the mode of the salt binding and the intricate interplay of cation coordination and hydrogen bonding in these complexes. When complexed with $\mathrm{NaBr}$, the ribopyranoside is in the ${ }^{1} C_{4}$ shape whereas ribose with no salt present has the ${ }^{4} C_{1}$ shape. It is also demonstrated that such complexes can be easily prepared in solid state reaction using a ball mill.
\end{abstract}

() 2011 Published by Elsevier Ltd.

\section{Introduction}

Complexes of disaccharides, cyclodextrins, and oligosaccharides with various metal salts have been known for some time. ${ }^{1}$ Curiously enough, these complexes have been seldom studied despite their obvious biological and dietary implications such as for the important, simple oral rehydration therapy. In the case of mono-

40 saccharides, particularly, only few examples with alkali metal salts have been reported. ${ }^{1-7,11-14}$ Ribose is no exception: crystalline complexes with sodium salts have not been described for either D-ribose (1) or its derivatives. Ribose itself could also be considered understudied from a structural standpoint. Only recently was its crystal structure reported. ${ }^{8}$

Recently, during the production of D-ribono-1,4-lactone (2) one of us (IP) isolated a new complex of $\mathbf{2}$ with sodium bromide $(\mathbf{2 b}) .^{9}$ In that new complex, physical properties, such as solubility, melting point, and optical rotation were found to deviate from the

50 known data of D-ribono-1,4-lactone synthesized first by $E$. Fischer. ${ }^{10}$ The composition of the compound was established by microanalysis, IR, and ${ }^{1} \mathrm{H}$ NMR spectroscopy as a 1:1 complex of the two components. Further experiments led to the isolation of a new complex of methyl $\beta$-D-ribopyranoside with sodium bromide $(\mathbf{3 b})^{4}$

\footnotetext{
* Corresponding author. Tel.: +36 1438 1161; fax: +36 13257547.

E-mail addresses: mcz@chemres.hu (M. Czugler), pintis@elte.hu (I. Pintér).
}

Increasing interest in the role of D-ribose and its derivatives in biological processes prompted us to examine the formation and the structure of their complexes with sodium halides. Beforehand bis(sucrose) tris(sodium iodide) trihydrate and the dihydrate of the sodium bromide complex of sucrose were characterized by single crystal X-ray diffraction around $19 \widehat{46} .{ }^{11,12}$ Only few more structural studies were reported later. Gilli and co-workers, ${ }^{13,14}$ aside from reporting advanced structure models for the sucrose $\mathrm{NaBr} \cdot 2 \mathrm{H}_{2} \mathrm{O}$ system and the sodium iodide dihydrate $2: 3: 3$ complex by X-ray crystallography also performed theoretical calculations on these crystals. Ferguson et al. described ${ }^{7}$ the correct crystal structure of the glucose. $\mathrm{NaCl} \cdot \hat{m}$ monohydrate complex, contrasting an earlier work that reported wrong unit cell, Laue- and space group. ${ }^{6}$ They also established isostructurality of the $\mathrm{NaBr}$ and $\mathrm{NaI}$ complexes, and also first described that the glucose $\mathrm{NaCl}$ complex can be prepared by grinding the components

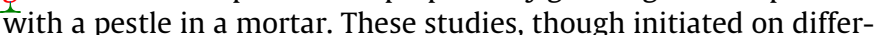
ent grounds can be somehow linked to oral rehydration therapy yielding to enhanced salt-sugar-water transport in men. A new complex of cellobiose. $2 \mathrm{NaI} \cdot 2 \mathrm{H}_{2} \mathrm{O}$ was also studied recently. ${ }^{15}$

\section{Results and discussion}

The syntheses of the complexes were performed under very simple reaction conditions. ${ }^{9}$ D-Ribose (1), D-ribono-1,4-lactone (2), and methyl $\beta$-D-ribopyranoside (3) in methanol or in acetone wêre mixed with each sodium salt under stirring at room

0008-6215/\$ - see front matter (c) 2011 Published by Elsevier Ltd. doi:10.1016/j.carres.2011.03.014 
temperature to give the new complexes $\mathbf{1 a - 1 c}$ and $\mathbf{2 c}$, respectively. In almost all cases the sugar and the salt dissolved within 15$30 \mathrm{~min}$. The crystalline complexes were precipitated with an appropriate solvent as ethyl acetate or acetone. Crystals of D-ribose $\mathrm{NaCl}$ (1a) spontaneously separated from the solution. The crystalline products were purified by dissolving in methanol and precipitating with either ethyl acetate or acetone.

Crystals of new D-ribose. $\mathrm{NaCl}(\mathbf{1 a})$, D-ribose. $\mathrm{NaBr}(\mathbf{1 b})$, D-ribose-NaI (1c) and D-ribono-1,4-lactone.NaI (2c) were characterized with melting points, optical rotations, and determination of the halide content.
X-ray diffraction analysis of $\mathbf{2} \mathbf{b}$ revealed the presence of a water molecule (Fig. 1). The structure determination shows that the crystal structure $\mathbf{2 b}$ is typical catena-structure with differing cation, anion and molecular involvement of the components (Fig. 2).

Sodium cations occupy two non-equivalent crystallographic sites (special positions) thus giving rise to two different $\mathrm{Na}^{+}$cation kinds. From these properties of this crystal it follows that a real stoichiometry of the $\mathbf{2 b}$ crystal is best described by $2: 2: 2$.

One of the cations is in a salt bridge linking to the $\mathrm{Br}^{-}$anion also coordinating to water and to the primary - $\mathrm{OH}$ of the ribonolactone,

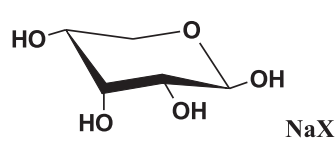

1a: $\mathbf{X}=\mathbf{C l}$

$1 \mathrm{~b}: \mathrm{X}=\mathrm{Br}$

1c: $X=I$

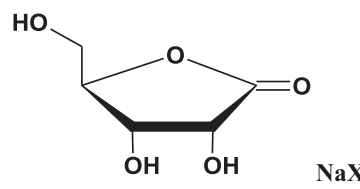

2b: $\mathrm{X}=\mathrm{Br}$

2c: $X=I$

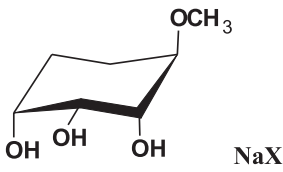

3b: $\mathbf{X}=\mathbf{B r}$

The structure of $\mathbf{1 a}$ was corroborated also by ${ }^{1} \mathrm{H}$ and ${ }^{13} \mathrm{C}$ NMR spectra. In accordance with the values of the optical rotation, ${ }^{1} \mathrm{H}$ NMR spectra of the complex 1a in aqueous solution exhibited the change of the concentration of the isomers of $\mathbf{1}$ into the equilibrium. After $1 \mathrm{~h}$ the concentration of $\beta$-pyranose (1a $\beta-p)$ was found to be the highest (58.4\%), while that of the $\alpha$-pyranose (1a $\alpha-p)$ decreased to $21.9 \%$. The equilibrium concentration of the $\beta$-furanose (1a $\beta-f$ ) and that of the $\alpha$-furanose (1a $\alpha-f$ ) were $12.4 \%$ and $7.3 \%$, respectively.

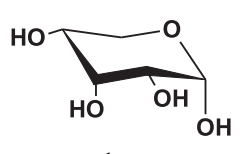

1a $\alpha-p$

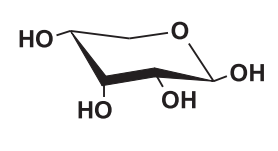

$1 \mathbf{a} \beta-p$

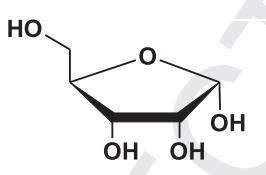

1a $\alpha-f$ while the other one is fully shielded from the anion, a frequent phenomenon in hydrated salt structures such as, for example, in Ref. 7. It is, however, remarkable that the secondary -OH groups of the furanoid ring solely coordinate this second sodium cation site. Both $\mathrm{Na}^{+}$cations are six-coordinated with comparable coordination geometries (cf. Table 2).

Cations are fused into two independent alternating ionic sheets along the planes at $\{x, y, 0\}$ and $\{x, y, 1 / 4\}$, comprised by the hydrated<smiles></smiles>

salt sheet and the cationic sheet fully shielded by D-ribono-1,4-lactone layers (Fig. 2), respectively.

Space group $C 222_{1}$ permits the development of perfect $C_{2}$-symmetric polymeric chains and obviously water uptake is useful in complementing the anion coordination sphere. Hydrogen bonding plays only a supplementary role as also shown by the $\mathrm{H}$-atom positions. These are always directed such that the lone pairs of the $-\mathrm{OH}$ groups are readily accessible for coordination (cf. Supplementary data).

In contrast to $\mathbf{2 b}$ crystal structure, $\mathbf{2 c}$ (Fig. 3) shows a totally asymmetric unit cell and a space group lacking any but translational symmetries with a 2:1:1 lactone:salt:water stoichiometry. The only $\mathrm{Na}^{+}$cation is shielded by two D-ribono-1,4-lactone moieties. Thus, there is no salt bridge link between cation and anion and the $\mathrm{Na}^{+}$cation is also six-coordinated. A non-crystallographic 2fold rotation axis appears in this structure but this will not be matured into a crystallographic symmetry in the $P 1$ space group. Water uptake is also needed for this crystal to form and water, together with the primary -OH group, is active in keeping $\mathrm{Br}^{-}$off of the cation. Comparison of respective bonds in these furanoid moieties indicates comparable geometries in $\mathbf{2},{ }^{16}$ in $\mathbf{2 b}$ and in $\mathbf{2 c}$ thus demonstrating neutral sugar forms (Table 3 ).

A Cambridge Structural Database ${ }^{17}$ analysis shows that the expected $\mathrm{C} 3-\mathrm{O} 3$ bond length in furanose type structures has a mean pyranoside (3) with $\mathrm{NaBr}$ (Table 1 ). Crystals were grown by vap diffusion using either acetone or ethyl acetate as anti-solvents into either a lactone-salt or riboside-salt solution in methanol. ${ }^{9}$ Welldevelopề single crystals grew within few days. 
Table 1

Crystal data and structure refinement characteristics of $\mathbf{2 b}, \mathbf{2 c}$, and $\mathbf{3 b}$

\begin{tabular}{|c|c|c|c|}
\hline & $\mathbf{2 b}$ & $2 c$ & 3b \\
\hline Empirical formula & $\mathrm{C}_{5} \mathrm{H}_{10} \mathrm{BrNaO}_{6}$ & $\mathrm{C}_{10} \mathrm{H}_{18} \mathrm{INaO}_{11}$ & $\mathrm{C}_{6} \mathrm{H}_{12} \mathrm{BrNaO}_{5}$ \\
\hline Formula weight & 269.02 & 464.14 & 267.05 \\
\hline Temperature & $93(2) \mathrm{K}$ & $295(2) \mathrm{K}$ & $93(2) \mathrm{K}$ \\
\hline Radiation, Mo $\mathrm{K} \alpha, \lambda$ & $0.71070 \AA$ & $0.71070 \AA$ & $0.71070 \AA$ \\
\hline Crystal system & Orthorhombic & Triclinic & Monoclinic \\
\hline Space group & $C 222_{1}$ & $P 1$ & $P 2_{1}$ \\
\hline Unit cell, $a(\AA)$ & $7.333(2)$ & $6.0080(12)$ & $7.1795(13)$ \\
\hline$b(\AA)$ & $9.548(3)$ & $6.0473(11)$ & $6.0318(10)$ \\
\hline$c(\AA)$ & $25.7513(1)$ & $11.4790(16)$ & $10.8500(16)$ \\
\hline$\alpha\left(^{\circ}\right)$ & 90 & $83.418(7)$ & 90 \\
\hline$\beta\left(^{\circ}\right)$ & 90 & $76.858(7)$ & $96.192(8)$ \\
\hline$\gamma\left({ }^{\circ}\right)$ & 90 & $77.597(9)$ & 90 \\
\hline Volume $\left(\AA^{3}\right)$ & $1803.1(7)$ & $395.71(12)$ & $467.12(13)$ \\
\hline$Z$ & 8 & 1 & 2 \\
\hline Density (calcd) $\mathrm{Mg} / \mathrm{m}^{3}$ & 1.982 & 1.95 & 1.9 \\
\hline Absorption coefficient, $\mu$ & $4.603 \mathrm{~mm}^{-1}$ & $2.105 \mathrm{~mm}^{-1}$ & $4.434 \mathrm{~mm}^{-1}$ \\
\hline Crystal color & Colorless & Colorless & Colorless \\
\hline Crystal description & Prism & Brick & Plate \\
\hline Crystal size (mm) & $0.35 \times 0.30 \times 0.30$ & $0.32 \times 0.24 \times 0.22$ & $0.38 \times 0.28 \times 0.07$ \\
\hline Absorption correction & Empirical & Numerical & Numerical \\
\hline Max/min transmission & $1.000 / 0.589$ & $0.742 / 0.637$ & $0.832 / 0.272$ \\
\hline$\theta$-range data collection $\left(^{\circ}\right)$ & $3.16 \leqslant \theta \leqslant 27.48$ & $3.46 \leqslant \theta \leqslant 33.14$ & $3.25 \leqslant \theta \leqslant 34.97$ \\
\hline Reflections collected & 20576 & 30598 & 31184 \\
\hline Completeness to $2 \theta$ & 0.999 & 0.998 & 0.986 \\
\hline Independent reflections, $R_{\mathrm{int}}$ & $2073,0.033$ & $5822,0.022$ & $3958,0.059$ \\
\hline Reflections $I>2 \sigma(I)$ & 2047 & 5821 & 3862 \\
\hline Data/restraints/parameters & $2073 / 0 / 132$ & $5822 / 3 / 209$ & $3958 / 1 / 149$ \\
\hline Goodness-of-fit on $F^{2}$ & 1.126 & 1.165 & 1.179 \\
\hline Extinction coefficient & $0.00064(15)$ & $0.0044(11)$ & - \\
\hline Flack parameter & $0.009(7)$ & $0.007(8)$ & $0.023(8)$ \\
\hline Final $R$ for $[I>2 \sigma(I)] R_{1}, w R^{2}$ & $0.0157,0.0380$ & $0.0184,0.0428$ & $0.0336,0.0590$ \\
\hline $\mathrm{R}$ indices (all data) $R_{1}, w R^{2}$ & $0.0160,0.0381$ & $0.0184,0.0428$ & $0.0353,0.0595$ \\
\hline Max. and mean shift/esd & $0.001 ; 0.000$ & $0.001 ; 0.000$ & $0.001 ; 0.000$ \\
\hline Largest diff. peak/hole e $\AA^{-3}$ & $0.33 /-0.30$ & $0.37 /-0.40$ & $0.94 /-0.53$ \\
\hline
\end{tabular}

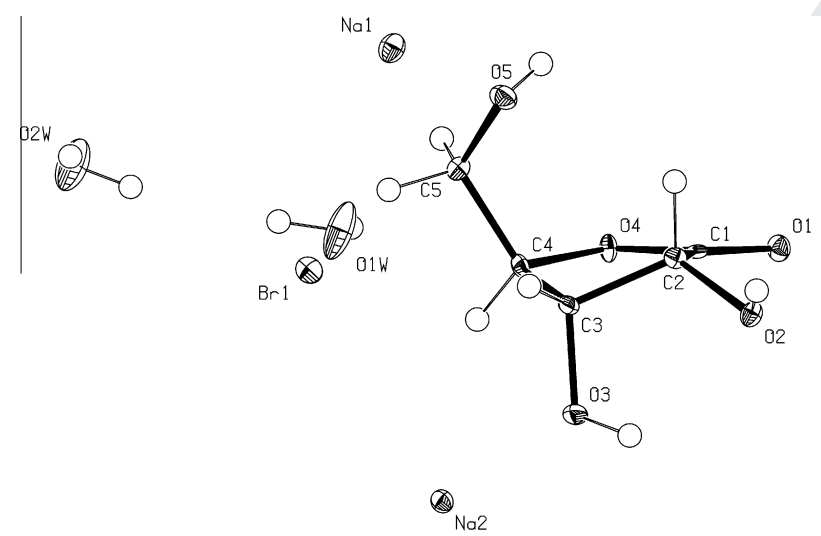

Figure 1. Asymmetric unit in the $\mathbf{2 b}$ crystal structure with $50 \%$ probability displacement ellipsoids.

bond length around 1.41 A thus the value in $\mathbf{2 b}$ can be regarded as significantly deviating.

Packing in $\mathbf{2 c}$ is less intriguing than in $\mathbf{2 b}$ but also maintains dominating ionic interactions and additional strong hydrogen bridges (cf. Supplementary data). Common to both $\mathbf{2 b}$ and $\mathbf{2 c}$ is the sixfôld cation coordination. This formal equivalence to the number of ligating $O$ atoms to 18 -crown- 6 complexes is realized through the symmetric coordination polyhedron in $\mathbf{2 b}$ and in an only slightly distorted one in $\mathbf{2 c}$. $\mathrm{Na}^{+}$cation distances from the planes of two equatorial and an axial ligand atom show a shorter $(1.34 \AA$ ) and a longer value $(1.52 \AA)$ in $\mathbf{2 b}$. The shorter value is for the $\mathrm{Na}^{+}$cation bound by solely secondary $\mathrm{O}$ atoms, while the other is for the mixed coordination sphere. Similarly short distances

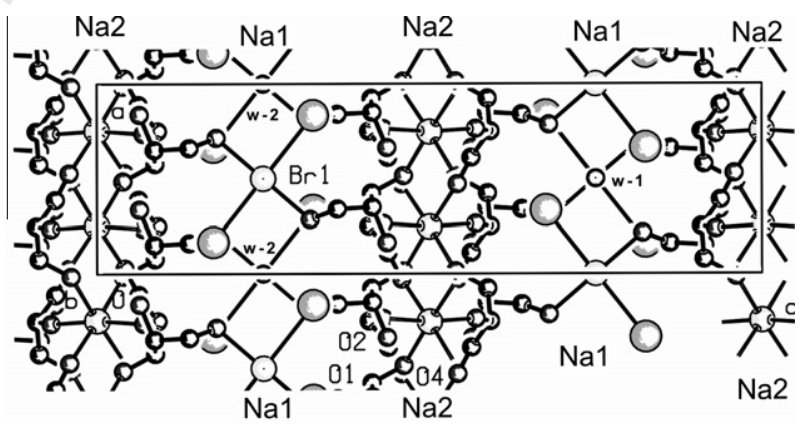

Figure 2. Infinite sheet structures in $\mathbf{2 b}$ showing isolated $\mathrm{Na}^{+}$ion layers involving water and direct anion/cation contacts as well as fully separated $\mathrm{Na}^{+}$ion layers shielded by D-ribono-1,4-lactone arrays. Atom coding is shown for some $\mathrm{Na}, \mathrm{Br}$, ribose $\mathrm{O}$, and water molecules while $\mathrm{H}$ atoms are omitted for clarity.

Table 2

Coordination distances for $\mathbf{2 b}$, for $\mathbf{2 c}$, and for $\mathbf{3 b}$ (in $\AA$ )

\begin{tabular}{|c|c|c|c|c|c|}
\hline $2 \mathbf{b}$ & & $2 c$ & & 3b & \\
\hline $\mathrm{Na} 2-03^{\mathrm{a} \#}$ & $2.359(2)$ & $\mathrm{Na} 1-021$ & $2.347(2)$ & $\mathrm{Br} 1-\mathrm{Na} 1$ & $3.076(1)$ \\
\hline $\mathrm{Na} 2-\mathrm{O} 1^{\mathrm{b} \#}$ & $2.388(2)$ & $\mathrm{Na} 1-022$ & $2.402(1)$ & $\mathrm{Na} 1-\mathrm{O} 5^{\mathrm{i}}$ & $2.661(2)$ \\
\hline \multirow[t]{2}{*}{$\mathrm{Na} 2-\mathrm{O} 2^{\mathrm{c \#}}$} & $2.418(2)$ & $\mathrm{Na} 1-011^{\mathrm{f}}$ & $2.436(2)$ & $\mathrm{Na} 1-\mathrm{O} 4^{\mathrm{i}}$ & $2.483(2)$ \\
\hline & & $\mathrm{Na} 1-032$ & $2.390(2)$ & $\mathrm{Na} 1-\mathrm{O} 4^{\mathrm{h}}$ & $2.463(2)$ \\
\hline $\mathrm{Br} 1-\mathrm{Na} 1^{\#}$ & $3.117(1)$ & $\mathrm{Na} 1-031^{\mathrm{g}}$ & $2.421(2)$ & $\mathrm{Na} 1-\mathrm{O} 3$ & $2.421(2)$ \\
\hline $\mathrm{Na} 1-01 w^{\mathrm{d}}$ & $2.291(2)$ & $\mathrm{Na} 1-012$ & $2.455(2)$ & $\mathrm{Na} 1-\mathrm{O} 3^{\mathrm{h}}$ & $2.461(2)$ \\
\hline $\mathrm{Na} 1-05^{\#}$ & $2.405(1)$ & & & $\mathrm{Na} 1-\mathrm{O} 4^{\mathrm{i}}$ & $2.507(3)$ \\
\hline $\mathrm{Na} 1-02 w^{e}$ & $2.267(3)$ & & & $\mathrm{Na} 1-\mathrm{O} 4^{\mathrm{h}}$ & $2.704(2)$ \\
\hline
\end{tabular}

Symmetry codes to generate equivalent atoms: in $\mathbf{2 b}: a=x,-y,-z+1$; $b=x+1,-y,-z+1 ; c=x+1 / 2,-y+1 / 2-1,-z+1 ; d=x+1 / 2-1, y+1 / 2, z ; e=x+1 /$ $2-1, y+1 / 2-1, z$; in $2 \mathbf{c}: f=x-1, y, z+1 ; g=x, y-1, z+1 ;$ in $3 \mathbf{b}: h=2-x, y-1 / 2$, $1-z ; i=x, y-1, z$.

\# These distances are replicated by the twofold symmetry. 
a

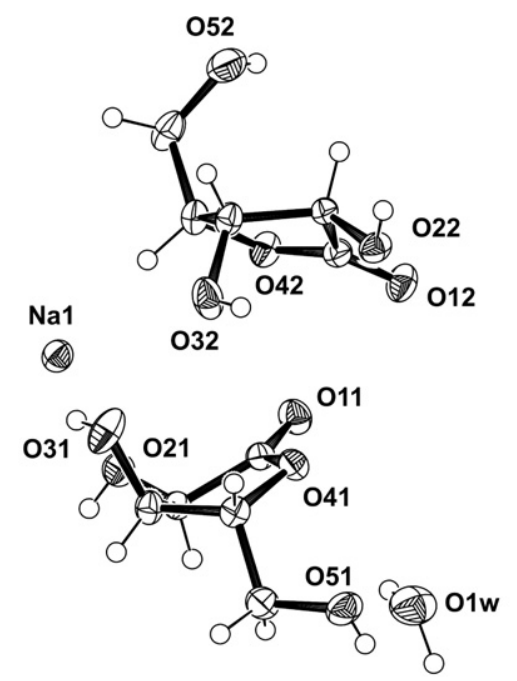

11

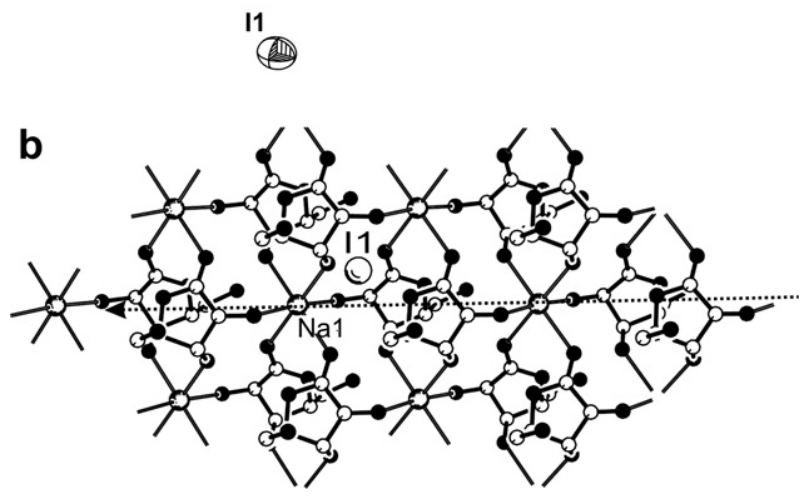

Figure 3. (a) ORTEP style plot of the 2c asymmetric unit content showing heteroatomic numbering (50\% probability displacement ellipsoids). (b) The isolated $\mathrm{Na}^{+}$ from its counter-ion and showing an approximate non-crystallographic twofold axis relating lactone rings (dotted line).

Table 3

Bond lengths ${ }^{\mathrm{c}}(\AA)$ of $\mathbf{2},{ }^{16} \mathbf{2 b}$ and $\mathbf{2 c}$

\begin{tabular}{llllll}
\hline Bond & $\mathbf{2}$ & $\mathbf{2 b}$ & $\mathbf{2 c}^{\mathrm{a}}$ & $\mathbf{2 c}^{\mathrm{b}}$ & Mean \\
\hline O1-C1 & 1.203 & 1.206 & 1.204 & 1.206 & 1.205 \\
O2-C2 & 1.403 & 1.410 & 1.402 & 1.413 & 1.407 \\
O3-C3 & 1.417 & 1.433 & 1.424 & 1.420 & 1.424 \\
O4-C4 & 1.467 & 1.486 & 1.472 & 1.472 & 1.474 \\
O4-C1 & 1.354 & 1.341 & 1.334 & 1.330 & 1.340 \\
O5-C5 & 1.431 & 1.430 & 1.417 & 1.425 & 1.426 \\
C1-C2 & 1.510 & 1.522 & 1.524 & 1.513 & 1.517 \\
C2-C3 & 1.525 & 1.525 & 1.529 & 1.526 & 1.526 \\
C3-C4 & 1.538 & 1.523 & 1.521 & 1.529 & 1.528 \\
C4-C5 & 1.516 & 1.514 & 1.508 & 1.507 & 1.512 \\
\hline
\end{tabular}

$\bar{\equiv}$ hpound 2c has two independent lactone molecules in the asymmetric unit.

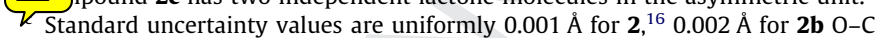
bonds and $0.002-3 \AA$ for the $\mathrm{C}-\mathrm{C}$ ones, $0.002 \AA$ for $2 \mathrm{c} \mathrm{O}-\mathrm{C}$ bonds and $0.002-3 \AA$ for the $\mathrm{C}-\mathrm{C}$ ones.

from the like planes in $\mathbf{2 c}$ are 1.32 and $1.36 \AA$. Thus, the three pairs of oxygens ligating $\mathrm{Na}^{+}$cations in the sixfold manner display an exaggerated pseudo-crown like binding. These structures probably present the minimal steric and electronic conditions for non-covalent organized binding for $\mathrm{Na}^{+}$. Another observation pertains to the pseudo-symmetric arrangements of the lactone ligands around the translation dependent sodium sites (Fig. 3b), lending a rather regular arrangement in a non-orthogonal crystal lattice. The lactone rings form an integral part of the catena-structure.

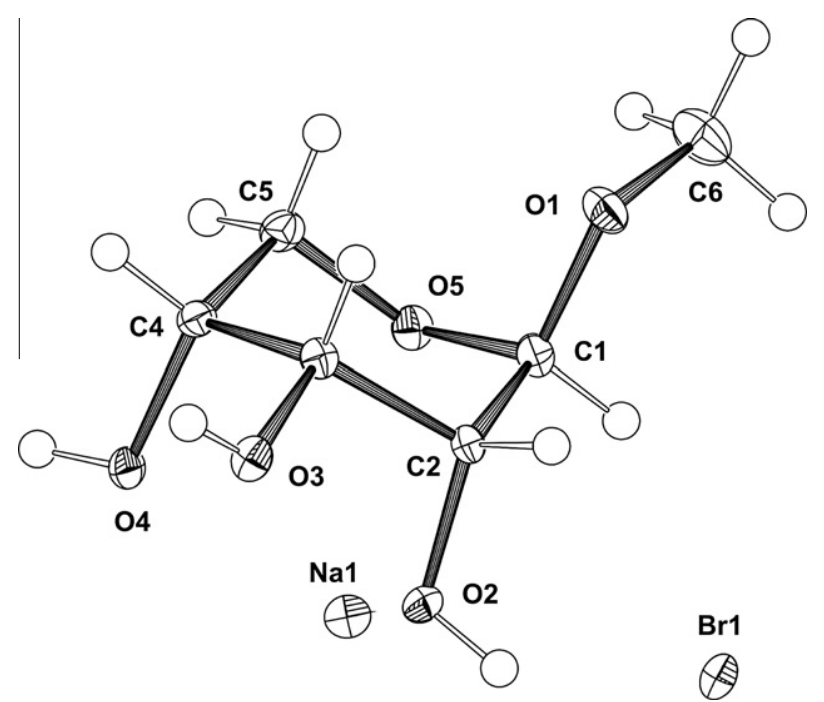

Figure 4. 50\% Probability displacement ellipsoids plot of the asymmetric unit of the 3b complex with atomic numbering.

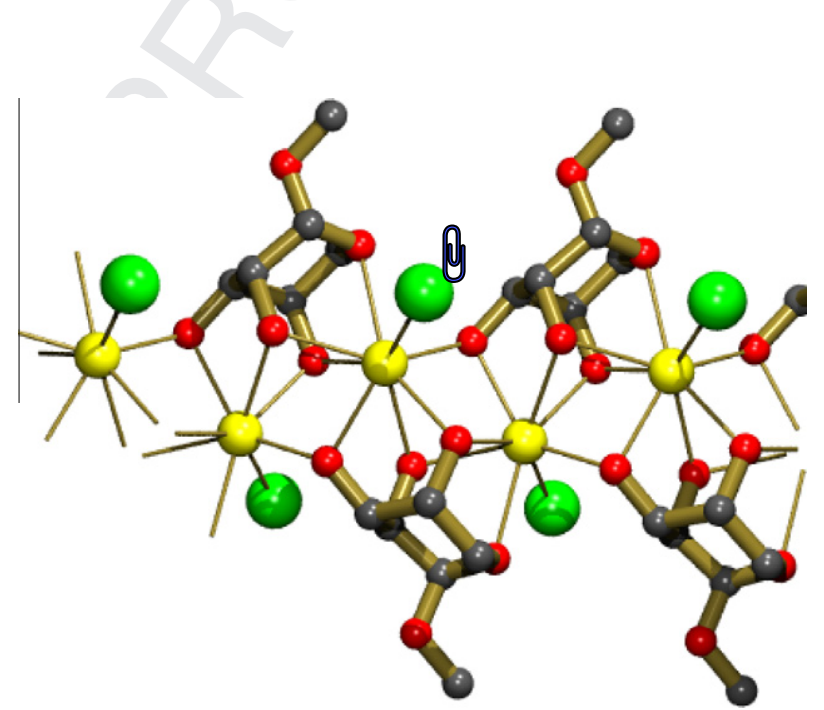

Figure 5. An excerpt from the $\mathbf{3 b}$ crystal structure showing the salt binding region over the secondary $-\mathrm{OH}$ surface, with atom color coding but omitting all $\mathrm{H}$ atoms for clarity.

Crystal structure $\mathbf{3 b}$ has $1: 1$ stoichiometry for $3: \mathrm{NaBr}$ and is deviating from the other two in that there is no water in this crystal (Fig. 4). H-bonding only plays a subordinate role here in a way of complementing the obviously more stern ionic interactions. Sodium cation is basically six-coordinated as far as the shortest distances in 3b to six $\mathrm{O}$ atoms go. Longer close contacts between the anion and the cation and another $\mathrm{O}$ atom do exist, too. It is also interesting that neighboring $\mathrm{Na}^{+}$cations approach each other at 3.515(2) A distance. $\mathrm{Na}^{+}$is sitting in the mid of a distorted polyhedron made from oxygen atoms and the anion (Fig. 5). As before secondary $-\mathrm{OH}$ groups dominate in these interactions and actually function much like a 'solvation sphere' toward the salt-sheet.

\subsection{Ring puckering, sodium cation binding, and the H-bridge patterns}

\subsubsection{Ring shapes of the furanose ring}

Cremer and Pople ${ }^{18}$ ring puckering analysis by the aid of PLA$\mathrm{TON}^{19}$ to symmetrical forms of five-membered rings shows that 
Table 4

Ring puckering parameters of the $\mathbf{2} \mathbf{b}$ and $\mathbf{2} \mathbf{c}^{\mathrm{a}}$ ribofuranose rings as compared for the $\mathbf{2}$ crystal structure $\mathrm{e}^{16}$

\begin{tabular}{llcllll}
\hline & $\mathrm{Q}_{(2)}(\AA)$ & \multicolumn{1}{c}{$\Phi_{(2)}\left({ }^{\circ}\right)$} & $P\left(^{\circ}\right)$ & $\tau\left(^{\circ}\right)$ & $\Delta\left(^{\circ}\right)$ & Form \\
\hline $\mathbf{2 b}$ & $0.309(2)$ & $95.5(3)$ & $184.4(2)$ & $31.5(1)$ & 368.9 & ${ }^{2} \mathrm{~T}_{3}$ \\
$\mathbf{2 c}^{\mathrm{a}}$ & $0.346(2)$ & $100.3(2)$ & $190.2(2)$ & $35.0(1)$ & 380.4 & $\mathrm{E}_{3}$ \\
$\mathbf{2} \mathbf{c}^{\mathrm{a}}$ & $0.302(2)$ & $95.5(3)$ & $184.3(2)$ & $30.7(1)$ & 368.6 & ${ }^{2} \mathrm{~T}_{3}$ \\
$\mathbf{2}$ & 0.38 & 99.2 & 188.6 & 38.5 & 377.1 & $\mathrm{E}_{3}$
\end{tabular}

$\overline{\text { For } \mathrm{Q}_{(2)} \text { and } \Phi_{(2)} \text { definitions see: Ref. } 18, P \text { and } \tau \text { pseudo rotation parameters: Ref. }}$ 20, $\Delta$ is defined in Ref. 21.

a Compound $\mathbf{2 c}$ has two independent lactone rings in its asymmetric unit.

the furanose rings are either twisted on the $\mathrm{C} 2-\mathrm{C} 3$ bond or with $\mathrm{C} 3$ on the flap forms (Table 4). This latter is the ring shape in the uncomplexed 2 suggesting that these rings can adapt to the steric and electronic conditions of the salt complexation via even the relative slight adjustments possible in their overall shape. In other words one can state that this ring is preformed to complexation. This of course is in agreement with earlier analyses by Angyal. ${ }^{2}$ It is to be noted though that mainly due to the spatial constraints exerted by the largely predetermined geometry of the $04 /$ $\mathrm{C} 2>\mathrm{C} 1=\mathrm{O} 1$ group only minor puckering excursions are permitted, as a fit of the two lactone rings attests (see Supplementary Fig.).

\subsubsection{Ring shapes of the pyranose ring}

The puckering analysis ${ }^{19}$ shows the pyranose ring in $\mathbf{3 b}$ adopting a shape similar to a chair (Table 5). Parameters for the ${ }^{1} \mathrm{C}_{4}$-form are given (Table 5 , second row). The minor deviation from the canonical C form ${ }^{19,22}$ may be thought of as a snapshot on the pseudo-rotation pathway traversing through slight twists toward the perfect ${ }^{1} \mathrm{C}_{4}$ chair in $\mathbf{3 b}$ (see Fig. 4). This is in a striking contrast to the parent ribopyranose that has a nearly ideal canonical ${ }^{4} C_{1}$ chair form. The evolution of this unusual chair form may most probably be attributed to the sodium cation coordination furnishing another peculiar aspect of this complex chemistry.

As suggested by Angyal, ${ }^{2}$ the $a x-e q-a x$ (aea) sequences in pyranoses promote metal ion complexation. This clearly applies for $\mathbf{3 b}$
Table 5

Ring puckering parameters ${ }^{18,22}$ of the $\mathbf{3 b}$ ribopyranose ring compared for the ribose $\mathbf{3}^{\mathrm{a}}$ crystal structure $^{8}$

\begin{tabular}{lllrl}
\hline & $\mathrm{Q}(\AA)$ & $\left(^{\circ}\right)$ & \multicolumn{1}{c}{$\Phi\left(^{\circ}\right)$} & Form \\
\hline $\mathbf{3 b}^{\mathrm{b}}$ & $0.560(2)$ & $6.1(2)$ & $262(2)$ & ${ }^{1} \mathrm{C}_{4}$ \\
$\mathbf{3 - 1}^{8}$ & $0.543(8)$ & $3.0(8)$ & $295(21)$ & ${ }^{4} \mathrm{C}_{1}$ \\
${\mathbf{3}-\mathbf{2}^{8}}^{0}$ & $0.619(8)$ & $3.1(7)$ & $25(15)$ & ${ }^{4} \mathrm{C}_{1}$ \\
\hline
\end{tabular}

a Compound $\mathbf{3}$ has two independent molecules in its asymmetric unit of form I, which is the only form analyzed here.

b Values correspond to C4 as pivot atom so as to yield to canonical description.

where the non-H substituents are $\mathrm{C}(2)-\mathrm{O}(2)$ : $a x, \mathrm{C}(3)-\mathrm{O}(3)$ : $e q$ and $\mathrm{C}(4)-\mathrm{O}(4)$ : $a x$. The $a x-a x$ disposition of both $\mathrm{C}(1)-\mathrm{O}(1)$ and $\mathrm{O}(5)-$ $\mathrm{Na}(1)$ does not appear to hinder cation binding either. The adoption of the new ring shape as well as the facile coordination sphere of $\mathrm{Na}^{+}$is complemented through a sheet-like organization of the ligand-cation environment (Fig. 5). The infinite catena-structure is apparent here, too, as is the eminent role of the secondary - $\mathrm{OH}$ groups lining up the salt-sheet surface. This layer of sodium ions can be plausibly visualized like a rolling stone over the undulating surface of the secondary $-\mathrm{OH}$ groups. The soft iodide anion attaches to the sides of this cation zigzag layer.

For a detailed overview of the H-bonding pattern the reader is referred to the Supplementary data. As to the general H-bonding tendency one should conclude that intermolecular contacts are mostly to the anions and to the water molecules. Only a few contacts between lactone and riboside are likely to correspond to hydrogen bonds.

\subsection{Solid state reactions}

We explored whether solvent-free preparation of such complexes is possible by carrying out initial attempts on $\mathbf{2 b}$ with dry powders of 2 and of $\mathrm{NaBr}$ in a ball mill. A low-energy vibrator mill was used and the progress of the events was followed by X-ray powder diffraction of samples taken at regular intervals for a total grinding time of $1 \mathrm{~h}$. Experiments on anhydrous mixtures of the

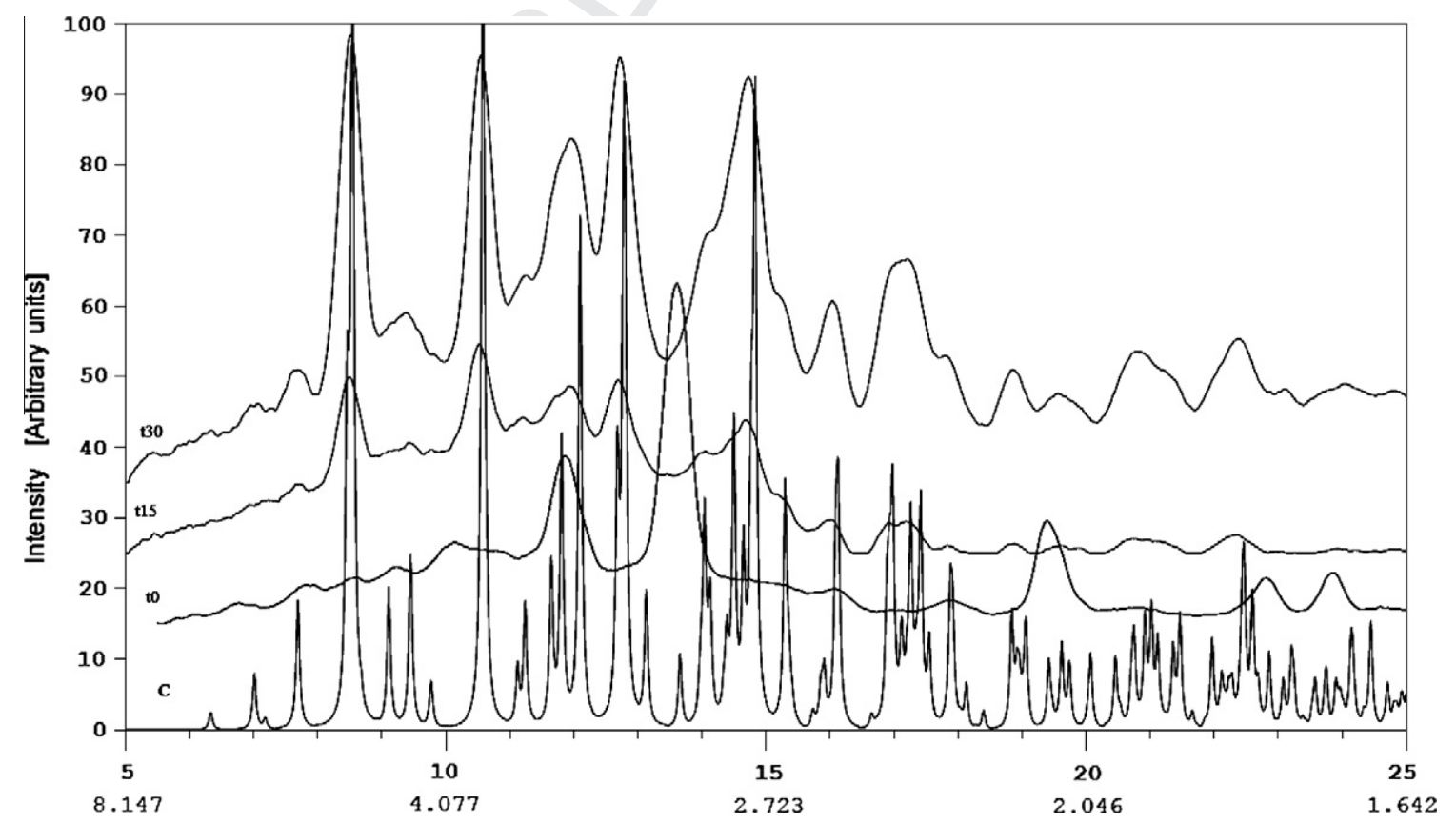

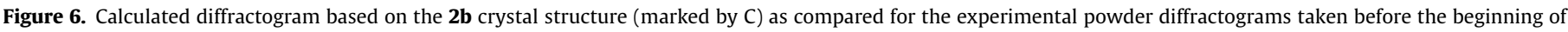

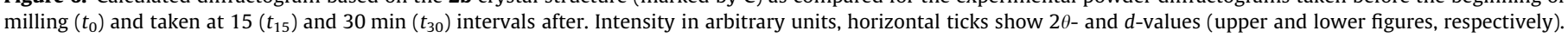


reactants indicated only increasing amounts of amorphous substance in powder diffractograms (not shown). This may also be related to the relative low energy of the mill applied. On the other hand addition of a trace of water to the mixture (to about $0.5 \mathrm{~g}$ total powder mass was added $5-10 \mu \mathrm{L}$ water) before grinding led to rapid evolvement of the complex as witnessed by the sequence of powder diffractograms (Fig. 6).

These show that the reaction, as compared for the ideal diffractogram calculated from the single-crystal X-ray structure, is nearly complete after half of an hour and no traces of the original physical mixture are visible. It is also clear that in accord with a general reaction path idea for ball mill reactions ${ }^{23}$ this very process goes through an amorphous intermittent state of the substances. Importance of the water involvement in $\mathbf{2} \mathbf{b}$ is also indicated by these pilot experiments, with faint similarity to solvent drop grinding. ${ }^{24}$

Thus, one can conclude that at least some of these complexes can be easily prepared in a 'green chemistry' fashion in short reaction times.

\subsection{Summary}

Carbohydrate derivatives seem to sustain an essential role both in the drug discovery ${ }^{25}$ and modifications as well as in the formulation of drugs. ${ }^{26}$ It did not escape our attention that these findings may bear direct or indirect relationships to the chemical behavior of some pharmaceutical additives in their solid state formulations. ${ }^{26}$ Work is in progress to describe further models of such as the salt complexes described herein as well as other related derivatives. Common to these structures are the formation of more or less regular infinite layer structures. Secondary $-\mathrm{OH}$ groups play a pivotal role and the involvement of the anion appears to be subordinate in the coordination of sodium cations. Bond valence model calculations ${ }^{27,28}$ also support the notion of highly regular and normal $\mathrm{Na}^{+}$-coordination spheres. In the crystal structures $\mathbf{2 b}, \mathbf{2 c}$, and $\mathbf{3 b}$ the sum of the bond valences are consistently (1.18 and 1.24, 1.17 and 1.15) over one as expected for $\mathrm{Na}^{+}{ }^{29}$ The secondary - $\mathrm{OH}$ groups generally appear on the top of the bond valances underlining their role in the cation binding. The individual bond valence numbers in these top ranges are by about $10 \%$ over and under 0.2 , respectively. These figures agree rather well for $\mathrm{Na}^{+}$coordination in biological milieu as analyzed for a large sample of enzyme crystal structures, ${ }^{29}$ perhaps underlining dietary implications for sugar-salt complexes (vide supra), too. The coordination volumes ${ }^{300}$ seem to agree either with the presence of the anion in the coordination sphere and or with the compactness of the coordination (octahedral volumes of 22.7 and of $18.1 \AA^{3}$ for $\mathrm{Na} 1$ and $\mathrm{Na} 2$ in $\mathbf{2 b}$, of $18.5 \AA^{3}$ for $\mathbf{2 c}$ and the larger polyhedron volume of $30.6 \AA^{3}$ for $\mathbf{3 b}$ ). Normally large molecules, such as crown ethers or other polyhydroxy macrocycles às, for example, modified calix-arenes or pyrogallarenes ${ }^{31}$ are needêd to effectively complex sodium salts. The crystal structures $\mathbf{2 b}, \mathbf{2 c}$ and $\mathbf{3 b}$ are also interesting in that respect that only rather small, neutral organic molecules are involved in forming these solid crystalline associations. Trivially they are inherently chiral and easy to obtain.

\section{Experimental}

\subsection{General methods}

Melting points were determined with Kofler micromelting apparatus and are uncorrected. For TLC precoated Merck Silica Gel 60 F254 plates were used and developed by charring with con$\mathrm{cd}_{2} \mathrm{SO}_{4}$. Eluents are given in each experiment. Optical rotations were measured with a Zeiss Polamat A polarimeter. Nuclear magnetic resonance spectra were determined on a DRX-500 BRUKER spectrometer. Assignment of ${ }^{1} \mathrm{H}$ and ${ }^{13} \mathrm{C}$ signals given is based on 2D-HSQc and 2D-HMBc spectra. Microanalysis was performed by the Microanalytical Laboratory of the Chemical Institute of Eötvös Loránd University. X-ray diffraction experiments were made on a Rigaku R-AXIS RAPID image plate diffractometer at low (93 K) and room temperature. This same machine was used recording powder diffractograms used for solid state reaction monitoring. Solid state reactions were affected in a Narva vibrator mill DDR-GM9458 type using either steel or agate balls in separate experiments.

\subsection{Synthesis of complexes}

\subsection{1. $D$-Ribose $\cdot \mathrm{NaCl}$ (1a)}

To D-ribose $(6.00 \mathrm{~g}, 40 \mathrm{mmol})$ in $\mathrm{MeOH}(25 \mathrm{~mL})$ was added sodium chloride $(2.34 \mathrm{~g}, 40 \mathrm{mmol})$ under stirring at room temperature. Under continuous stirring solids dissolved within some minutes, then crystals started to separate. The product was filtered to give white crystals $(4.90 \mathrm{~g})$ of the crude $1 \mathrm{a}$ melting at $158-161{ }^{\circ} \mathrm{C}$. From the mother liquor an additional crop of crystals

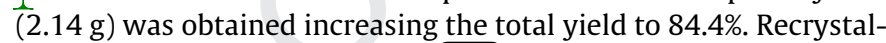
lization of a sample afforded $\bar{\equiv}$ crystals of the pure 1a, mp $165-167{ }^{\circ} \mathrm{C} ;[\alpha]_{D}-12.1\left(10^{\prime}\right), \rightarrow 44.5(1 \mathrm{~h})\left(\mathrm{H}_{2} \mathrm{O}, c \mathrm{c}\right)$. Calcd from $\hat{\mathrm{C}}_{5} \mathrm{H}_{10} \mathrm{O}_{5} \cdot \mathrm{NaCl}[\alpha]_{\mathrm{D}}-14.2$. TLC (EtOAC-MeOH 9:1) revealed only one spot of D-ribose $\left(R_{\mathrm{f}}, 0.09\right) .{ }^{1} \mathrm{H}$ NMR $\left(500 \mathrm{MHz}, \mathrm{D}_{2} \mathrm{O}\right) \delta 5.35(\mathrm{~d}$, $0.07 \mathrm{H}, J 3.8 \mathrm{~Hz}, \mathrm{H}-1 \stackrel{\alpha}{\alpha-\hat{f}) ; 5.22}(\hat{\mathrm{d}}, 0.12 \mathrm{H}, J 1.9 \mathrm{~Hz}, \mathrm{H}-1 \beta-f) ; 4.90$ $(\mathrm{d}, 0.58 \mathrm{H}, J 6.5 \mathrm{~Hz}, \mathrm{H}-1 \beta-p) ; 4.84(\mathrm{~d}, 0.22 \mathrm{H}, J 2.0 \mathrm{~Hz}, \mathrm{H}-1 \alpha-p)$; 4.18-3.50 (overlapped signals of the pentose protons in the equilibrium). ${ }^{13} \mathrm{C}$ NMR $\left(125 \mathrm{MHz}, \mathrm{D}_{2} \mathrm{O}\right) \delta 101.39,96.70,94.27,93.94$, $83.55,82.93,75.70,71.43,71.32,70.86,70.48,69.61,69.35$, 67.77, 67.66, 63.59, 63.43, 62.96, 61.84. Anal. Calcd for $\mathrm{C}_{5} \mathrm{H}_{10} \mathrm{ClNaO}_{5}$ (208.57): $\mathrm{Cl}, 17.00$. Found: $\mathrm{Cl}, 16.42$.

\subsubsection{D-Ribose $\cdot \mathrm{NaBr}(1 \mathrm{~b})$}

To a solution of D-ribose $(0.50 \mathrm{~g}, 3.3 \mathrm{mmol})$ in $\mathrm{MeOH}(10 \mathrm{~mL})$ was added sodium bromide $(0.35 \mathrm{~g}, 3.4 \mathrm{mmol})$ under stirring at room temperature. Under continuous stirring solids dissolved within some minutes, then the mixture was diluted with ethyl acetate $(15 \mathrm{~mL})$. The precipitate was filtered and washed with ethyl acetate to give white crystals of $\mathbf{1 b}(0.62 \mathrm{~g}, 72.1 \%), \mathrm{mp}$ 179-181 ${ }^{\circ} \mathrm{C} ;[\alpha]_{\mathrm{D}}-11.3\left(\mathrm{H}_{2} \mathrm{O}, c\right.$ 3). Calcd from $\mathrm{C}_{5} \mathrm{H}_{10} \mathrm{O}_{5} \cdot \mathrm{NaBr}[\alpha]_{D}$

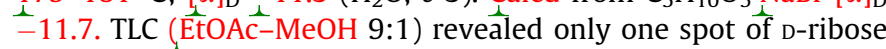
$\left(R_{\mathrm{f}}, 0.09\right)$. Anal. Calcd for $\mathrm{C}_{5} \mathrm{H}_{10} \cdot \mathrm{BrNaO}_{5}$ (253.02): $\mathrm{Br}, 31.58$. Found: $\widehat{\mathrm{Br}}, \widehat{\wedge} 31.06$.

\subsubsection{D-Ribose-NaI (1c)}

To a solution of sodium iodide $(0.23 \mathrm{~g}, 1.53 \mathrm{mmol})$ in acetone ( $5 \mathrm{~mL})$ D-ribose $(0.23 \mathrm{~g}, 1.53 \mathrm{mmol})$ was added under stirring at room temperature. Under continuous stirring solids dissolved within some minutes, then the mixture was diluted with ethyl acetate $(5 \mathrm{~mL})$. The precipitate was filtered and washed with ethyl acetate to give white crystals $(0 \rightleftharpoons 82.6 \%$ ) of pure 1c melting at $136-138{ }^{\circ} \mathrm{C} ;[\alpha]_{\mathrm{D}}-7.8\left(10^{\prime}\right), \rightarrow \overline{\mathrm{w}} .0$ (3 days) $\left(\mathrm{H}_{2} \mathrm{O}, c\right.$ 4.5). Calcd from $\mathrm{C}_{5} \mathrm{H}_{10} \mathrm{O}_{5}$. Nâl $[\alpha]_{\mathrm{D}}^{\hat{\lambda}}-10.7$. TLC (EtOAc-MeOH 9:1) revealed only one spot of D-ribose $\left(R_{\mathrm{f}}, 0.09\right)$. Anal. Calcd for $\mathrm{C}_{5} \mathrm{H}_{10} \cdot \mathrm{INaO}_{5}(300.02)$ : I, 42.30. Found: I, 41.99.

\subsubsection{D-Ribono-1,4-lactone-NaI (2c)}

To a solution of D-ribono-1,4-lactone $(0.44 \mathrm{~g}, 3 \mathrm{mmol})$ in a mixture of acetone $(5 \mathrm{~mL})$ and $\mathrm{MeOH}(1 \mathrm{~mL})$ sodium iodide $(0.45 \mathrm{~g}$, $3 \mathrm{mmol})$ was added under stirring at room temperature. Under continuous stirring solids dissolved within some minutes. Solvents were removed by distillation under reduced pressure and the crystalline residue was re-dissolved in acetone $(5 \mathrm{~mL})$. Dilution with ethyl acetate $(15 \mathrm{~mL})$ resulted in siow separation of pure $1 \mathbf{c}$ in white crystals $(0.64 \mathrm{~g}, 71.9 \%), \mathrm{mp} 71-72{ }^{\circ} \mathrm{C} ;[\alpha]_{\mathrm{D}}+12.3\left(\mathrm{H}_{2} \mathrm{O}, \mathrm{c} 4\right)$. 
Calcd for $2 \mathrm{C}_{5} \mathrm{H}_{8} \mathrm{O}_{5} \mathrm{~N} \mathrm{NaI} \cdot \mathrm{H}_{2} \mathrm{O}[\alpha]_{\mathrm{D}}+11.7$. Anal. Calcd for $\mathrm{C}_{10} \mathrm{H}_{18} \mathrm{INaO}_{\Lambda 1}$ (464.14): I, 27.34. Found: I, 27.13.

\subsection{Solid state reaction of 2 with $\mathrm{NaBr}$}

\subsubsection{Dry milling}

Equimolar amounts of 2 and $\mathrm{NaBr}$ of typically about $0.2-0.5 \mathrm{~g}$ were measured and homogenized by spatula mixing in an agate mortar for about 2-5 min. An aliquot powdery specimen was taken in an X-ray capillary. Remaining powder was transferred into $5 \mathrm{~cm}^{3}$ volume crucible of the vibrator mill and either steel or agate balls were applied for a total milling time of $1 \mathrm{~h}$. Milling was stopped at every $15 \mathrm{~min}$, material was scraped off the crucible walls, homogenized and minute amounts filled into X-ray capillaries. These capillaries were collected and subjected to $10-15 \mathrm{~min}$ $\mathrm{X}$-ray exposures on the R-Axis RAPID diffractometer. The X-ray powder diffraction control showed that the anhydrous samples had increasing amorphous content, but also that the characteristic peaks of the first physically mixed sample were still visible after $1 \mathrm{~h}$.

\subsubsection{Wet milling}

The above procedure was applied with the addition of $5-10 \mu \mathrm{L}$ water to about $0.5 \mathrm{~g}$ total mass of dry powder. Water was injected directly in the crucible after taking the 0 min powder sample. Subsequent procedure was identical as outlined above, with the early appearance of new peaks in the X-ray diffractograms.

\section{Acknowledgments}

Financial support by the Hungarian Research Fund (Grant No. OTKA T042642, K-75869 and K72973) and a diffractometer purchase grant from the National Office for Research and Technology (MU-00338/2003) are gratefully acknowledged. The European Union and the European Social Fund have provided financial support to the project under the grant agreement No. TÁMOP 4.2.1./ B-09/KMR-2010-0003. Authors are grateful to Drs. Antal Csámpai for ${ }^{1} \mathrm{H}$ and ${ }^{13} \mathrm{C}$ NMR spectra and István Sajó for redrawing Fig. 6. We also thank one of the referees of the paper for suggestions relating to the pseudo rotation pattern analysis in $\mathbf{3 b}$ and for general advices.

\section{Supplementary data}

Crystallographic data excluding structure factors have been
No. 608195-608197 for $\mathbf{2 b}, \mathbf{2 c}$ and $\mathbf{3 b}$, respectively. Copies of this information may be obtained free of charge from the Director, Cambridge Crystallographic Data Centre, 12 Union Road, Cambridge, CB2 1EZ, UK (fax: +44 1223 336033, e-mail: deposit@ccdc.cam.ac.uk or via: www.ccdc.cam.ac.uk). Supplementary data associated with this article can be found, in the online version, at doi:10.1016/j.carres.2011.03.014.

\section{References}

1. Rendleman, J. A., Jr. Complexes of Alkali Metals and Alkaline-Earth Metals with Carbohydrates In Advance in Carbohydrate Chemistry; Wolfrom, M. L., Tipson, R. S., Eds.; Academic Press: New York, 1967; Vol. 21, pp 209-271.

2. Angyal, S. J. Complexes of Metal Cations with Carbohydrates in Solution In Advance in Carbohydrate Chemistry and Biochemistry; Tipson, R. S., Horton, D., Eds.; Academic Press: New York, 1989; Vol. 47, pp 1-42.

3. Benner, $K$. et al On The Metal Binding Site of The Carbohydrates. In Carbohydrates as Organic Raw Materials IV; Praznik, W., Huber, A., Eds.; WUVUniversitätsverlag: Wien, 1998; pp 64-67.

4. Beevers, C. A.; Cochran, W. Nature 1946, 157, 872.

5. Rendleman, J. A., Jr. J. Org. Chem. 1966, 31, 1839-1845

6. Cho, Y.; Honzatko, R. B. Acta Crystallogr., Sect. C 1990, 46, 587-590.

7. Ferguson, G.; Kaitner, B. B.; Connet, E.; Rendle, B. F. Acta Crystallogr., Sect. B 1991, 47, 479-484.

8. Sisak, D.; McCusker, L. B.; Zandomeneghi, G.; Meier, B. H.; Blaeser, D.; Boese, R.; Schweizer, W. B.; Gilmour, R.; Dunitz, J. D. Angew. Chem., Int. Ed. 2010, 49, 4503-4505.

9. Pintér, I. Pol. J. Chem. 2005, 79, 323-328.

10. Fischer, E.; Piloty, O. Ber 1891, 24, 4214-4216.

11. Cochran, W. Nature 1946, 157, 231-233.

12. Beevers, C. A.; Cochran, W. Proc. R. Soc. London, Ser. A 1947, 190, 257-272.

13. Accorsi, C. A.; Bellucci, F.; Bertolasi, V.; Ferretti, V.; Gilli, G. Carbohydr. Res. 1989, 191, 91-104.

14. Accorsi, C. A.; Bellucci, F.; Bertolasi, V.; Ferretti, V.; Gilli, G. Carbohydr. Res. 1989, 191, 105-116.

15. Peralta-Inga, Z.; Johnson, G. P.; Dowd, M. K.; Rendleman, J. A., Jr.; Stevens, E. D.; French, A. D. Carbohydr. Res. 2002, 337, 851-888.

16. Kinoshita, Y.; Ruble, J. R.; Jeffrey, G. A. Carbohydr. Res. 1981, 92, 1-7. CSD REFCODE: BAGZAK.

17. Allen, F. H. Acta Crystallogr., Sect. B 2002, 58, 380-388.

18. Cremer, D.; Pople, J. A. J. Am. Chem. Soc. 1975, 97, 1354-1358.

19. Spek, A. L. Acta Crystallogr., Sect. D 2009, 65, 148-155.

20. Rao, S. T.; Westhof, E.; Sundaralingam, M. Acta Crystallogr., Sect. A 1981, 37, 421-425.

21. Altona, C.; Geise, H. J.; Romers, C. Tetrahedron 1968, 24, 13-32.

22. Dowd, M. K.; French, A. D.; Reilly, P. J. J. Carbohydr. Chem. 2000, 19, 1091-1114.

23. Kaupp, G. Cryst. Eng. Commun. 2006, 8, 794-804.

24. Trask, A. V.; Shan, N.; Motherwell, W. D. S.; Jones, W.; Feng, S.; Tan, R. B. H.; Carpenter, K. J. Chem. Commun. 2005, 880-882.

25. Carbohydrate-Based Drug Discovery; Wong, C.-H., Ed.; Wiley-VCH, 2003.

26. Byrn, S. R.; Xu, W.; Newman, A. W. Adv. Drug Deliv. Rev. 2001, 48, 115-136.

27. Brese, N. E.; O'Keeffe, M. Acta Crystallogr., Sect. B 1991, 47, 192-197.

28. Brown, I. D. The Chemical Bond in Inorganic Chemistry: The Bond Valence Model; Oxford University Press, 2002.

29. Nayal, M.; Di Cera, E. J. Mol. Biol. 1996, 256, 228-234.

30. Robinson, K.; Gibbs, G. V.; Ribbe, P. H. Science 1971, 172, 567-570.

31. Åhman, A.; Nissinen, M. Chem. Commun. 2006, 1209-1211. 